BULLETIN Bulletin hispanique

HISPANIQUE Université Michel de Montaigne Bordeaux

110-1 | 2008

Varia

\title{
El marco doctrinal de la tradición lingüística europea y los primeros misioneros de la Colonia
}

\section{Manuel Breva-Claramonte}

\section{(2) OpenEdition}

12 Journals

Edición electrónica

URL: https://journals.openedition.org/bulletinhispanique/431

DOI: 10.4000/bulletinhispanique.431

ISSN: $1775-3821$

Editor

Presses universitaires de Bordeaux

Edición impresa

Fecha de publicación: 1 junio 2008

Paginación: 25-59

ISBN: 978-2-86781-511-9

ISSN: 0007-4640

Referencia electrónica

Manuel Breva-Claramonte, «El marco doctrinal de la tradición lingüística europea y los primeros misioneros de la Colonia», Bulletin hispanique [En línea], 110-1 | 2008, documento 2, Publicado el 19 diciembre 2011, consultado el 18 septiembre 2021. URL: http://journals.openedition.org/ bulletinhispanique/431 ; DOI: https://doi.org/10.4000/bulletinhispanique.431 


\title{
El marco doctrinal de la tradición lingüística europea y los primeros misioneros de la Colonia
}

\author{
Manuel Breva-Claramonte \\ Universidad de Deusto, Bilbao - España
}

Dans ce travail, je me propose de reconstruire le cadre intellectuel et le corps de doctrines dans lesquels sinscrit l'action des premiers missionnaires de l'Amérique Hispanique. Nous pourrons ainsi mieux comprendre les objectifs de leurs grammaires et résoudre les contradictions apparentes que l'on a trouvées dans leurs textes. J'y examine la formation linguistique des évangélisateurs, les types de grammaires des langues indigènes qu'ils composaient, à deux niveaux : celui de la grammaire universelle et celui de l'étude de l'usage dans les langues particulières. J'aborde enfin la valeur de certains des métatermes dont ils se servent dans leurs descriptions.

En este trabajo, me propongo reconstruir el marco intelectual y doctrinal bajo el cual operaban los primeros misioneros de la América Hispana, lo que nos permitirá entender mejor la finalidad de sus gramáticas y aclarar supuestas contradicciones que se han encontrado en sus textos. Examino la formación lingüistica de los evangelizadores, el tipo de gramáticas de lenguas indígenas que componian, con dos niveles, el de la gramática universal y el del estudio del uso en los idiomas particulares. Por último, abordo el valor de algunos de los metatérminos que incluyen en sus descripciones.

This paper attempts to reconstruct the intellectual and doctrinal framework of the work of the first missionary grammarians in Spanish America. In the process, we will find it easier to understand the goals of their grammars and explain the apparent contradictions found in those texts. We examine the evangelists' linguistic training, the types of grammar they composed - on two levels: universal grammar and the study of usage in the various languages - and also consider several metaterms used in their descriptions.

Mots-clés : Linguistique des missionnaires - Tradition espagnole de la première époque - Grammaire - Modèle théorique - Analyse de données.

$B H i$, Tome 110, n $^{\circ} 1$ - juin 2008 - p. 25 à 59. 


\section{INTRODUCCIÓN}

$\mathrm{D}$ ESDE principios del siglo XIX hasta la actualidad han surgido críticas injustas con relación a las gramáticas de los misioneros, las cuales en gran parte ignoraban el contexto intelectual en el que se movían. Por ejemplo, Guillermo Humboldt en su Versuch einer Analyse der Mexicanischen Sprache (1813, en Gesammelte Schriften 1905, Vol. 4:237-238) considera a los misioneros "poco aptos para indagar lenguas cuyas estructuras singulares les eran totalmente nuevas» y deplora que fuercen estas lenguas dentro "de las reglas estrechas de la gramática de Antonio de Nebrija o de cualquier otro pedante español». Otros historiógrafos de las gramáticas de los misioneros encuentran cierto número de contradicciones en ellas. Estas apreciaciones son ciertamente engañosas por ignorar el marco epistemológico en el que se desenvolvían o por evaluar dichas gramáticas desde un ambiente intelectual completamente distinto.

En este trabajo, me propongo reconstruir el marco intelectual y doctrinal en el que operaban los misioneros, lo que nos permitirá entender mejor la labor y la finalidad de sus gramáticas, así como aclarar por qué dichos juicios críticos y supuestas contradicciones son inexactos. Para llevar a cabo la reconstrucción del contexto en el que componían sus gramáticas de lenguas indígenas, he dividido este estudio en tres partes. La primera examina la educación que habían recibido los religiosos, en la que el latín desempeñaba un papel importante como lengua de cultura y como instrumento contrastivo de tipo práctico, así como el castellano, aunque éste en menor grado. La segunda se ocupa del modelo teórico que seguían, el cual comportaba un doble nivel: el nivel universal o nocional y el nivel del uso o manifestaciones de lo universal en las lenguas particulares. Por último, la tercera parte se centra en el valor que asignaban éstos a los metatérminos partícula, caso y declinación dentro de su modelo bipolar, que seguía la tradición europea. Todo ello nos autorizará a evaluar más justamente y dentro del espíritu propio de su tiempo, la labor lingüística que llevaron a cabo.

\section{FORMACIÓN, COMPOSICIÓN DE GRAMÁTICAS, Y PAPEL DEL LATÍN Y DEL CASTELLANO}

Al principio, la formación gramatical de los misioneros franciscanos, dominicos, agustinos y jesuitas tuvo lugar en Europa. Éstos solían viajar a la Colonia con edades comprendidas entre los 19 y los 30 ańos y, a veces, incluso superiores, una vez habían recibido una formación religiosa y humanística apropiada en los colegios de sus órdenes y en las universidades. Con el 
paso de los años, se fundaron colegios, escuelas de idiomas, seminarios, universidades y se instalaron las primeras imprentas en América (en México en 1540 y en Perú en 1580$)^{1}$, por lo que su formación continuó en la Colonia; es más algunos de ellos ya nacieron en los países donde se hablaban las lenguas indígenas ${ }^{2}$.

En Nueva España la situación lingüística era bastante favorable, ya que existía un idioma de uso extendido que era el náhuatl o mexicano. Pero, a pesar de todo, los frailes también se enfrentaron con dificultades de tipo lingüístico por las diferencias del náhuatl y de otras lenguas de mesoamérica con las europeas. Al principio tomaron notas y escribieron bosquejos gramaticales, breves vocabularios y textos religiosos básicos, que con el paso del tiempo se convirtieron en gramáticas, vocabularios y textos más complejos ${ }^{3}$. Antes de que Andrés de Olmos terminara su Arte del náhuatl en 1547, cuando ya había residido en México 19 años, Francisco Jiménez, ocho años después de su propia llegada, había escrito un Arte de la lengua mexicana, que utilizarían sus compañeros de la orden franciscana, y Alonso de Rengel, también franciscano, había compuesto otro en los año treinta. En el Prólogo al lector de su Arte, Olmos (1993) escribe que había considerado y visto lo que "sobre la misma materia [...] otros habían escrito", es decir que se benefició de lo escrito anteriormente, algo que era muy común en las tareas lingüísticas de los misioneros.

Estas artes del náhuatl circulaban de forma manuscrita y servían para acelerar el aprendizaje de los rasgos sistemáticos con importancia comunicativa de dicha lengua; eran gramáticas escritas para potenciar la labor evangelizadora de los misioneros y no para que los lingüistas europeos

1. Para las razones y las vicisitudes de la instalación de la primera imprenta en México, véase Griffin (1991) y cf. Galeote (2002-2003: 405-408).

2. Fray Andrés de Olmos (1491-1570), autor de una de las primeras gramáticas del náhuatl, no llegará a Nueva España hasta después de haber cumplido 37 años. José de Anchieta (15331597), autor de un Arte del tupinambá (1595), lengua hablada en Brasil, llegó a dicho país en 1553, después de haber estudiado en Coimbra (1548-1551); en Piritinanga (actual Sao Paulo), fue maestro de latín durante once años. El limense Padre Antonio Ruiz de Mendoza (1585-1652), por ejemplo, fue ya uno de los misioneros que nació en América, residiendo durante años (de 1612 a 1637) en la antigua provincia de Guairá, donde vivían los guaranís (región Brasileña colindante con el Paraguay de hoy); en el año 1640, publicó un arte y un vocabulario de la lengua guaraní.

3. En Nueva Granada, una región con gran diversidad de lenguas, encontramos bastantes pruebas de las dificultades lingüísticas con las que se toparon los misioneros en su labor evangelizadora. Se conservan escritos o apenas noticias personales de los misioneros y de sus trabajos de campo, como notas gramaticales, vocabularios y textos religiosos, muchos de ellos gracias a la labor del sabio José Celestino Mutis (1732-1808), que fue encargado de recoger estos trabajos para el proyecto de Catalina de Rusia. 
interesados en ellas (sobre todo a partir del siglo XVIII por otros motivos) las entendieran. En el Prólogo al lector ya citado, Olmos (1993) indica «Finalmente oso afirmar que cualquiera que esta senda siguiere o sabrá más de esta lengua mexicana o tetzcucana en un ańo que yo en XX». En su Carta Dedicatoria, Olmos (1993) señala a quienes va dirigida la gramática, «me bastará si en algo sirviera a los principiantes o si en verdad diere ocasión a otros más doctos que yo y de mayor ingenio para que completen lo que aquí se halla». En realidad, Olmos era consciente de algunas de sus limitaciones descriptivas como la carencia de un desarrollo más apropiado y completo del capítulo sobre letras (sonidos) y prosodia (silabas y acentos), aspectos que mejoraría en el siglo siguiente Antonio del Rincón (1556-1601) y Horacio Carochi (1579-1662). En la sección Al lector de su Arte de la lengua mexicana (1645), Carochi (1983) expone que las artes que hasta ahora habían salido a la luz eran algo oscuras y que por eso quiso "componer un Arte, tan clara, y adornada de ejemplos, que pudiese cualquiera por sí [sin maestros] con suficiente estudio aprender esta lengua». Existe, pues, con el paso del tiempo, un deseo lógico de mejorar y ampliar los distintos contenidos de las gramáticas precedentes y de convertirlas en obras más pedagógicas, más extensas y completas, y de más fácil comprensión. Domingo de Santo Tomás (1499-1570), en su Gramática o Arte (1560) del quechua (véase 1951, Prólogo al lector) muestra como ejemplo al propio Antonio de Nebrija, de quien dice «[...] enmendó su arte de la lengua latina por tercera vez». Y por eso, él deja la puerta abierta para que otros puedan ańadir lo que faltara o quitar lo superfluo.

El renovado interés de los lingüistas europeos por las lenguas indígenas a partir del siglo XVIII se observa claramente si se efectúa un seguimiento de fechas y porcentajes de publicaciones de gramáticas de estas lenguas. En realidad, un gran número de tratados de los misioneros de la América hispana circuló en forma manuscrita al principio, pues éstos se publicaron mayormente a partir de dicho siglo, cuando en Europa y más tarde en América resurgió con fuerza la preocupación por el estudio de las lenguas indígenas. Por ejemplo, el Arte de fray Andrés de Olmos, que se divulgó de forma manuscrita, en numerosos ejemplares, de los que todavía se conservan seis, no llegó a imprimirse hasta 1875, en Francia.

En general, los misioneros con la mejor formación lingüística y los mejor dotados para la gramática fueron los que compusieron las artes. Estaban preparados para ello por sus conocimientos de la tradición gramatical europea y por sus cualidades innatas como lingüistas. Por ejemplo, el historiador franciscano Gerónimo de Mendieta (1525-1604) afirma que «Fr. Andrés de Olmos fue el que sobre todos tuvo don de lenguas» (véase Mendieta 
1870:550). Olmos investigó el totonaca y el náhuatl, escribiendo sendas artes de estas lenguas y pudo haber escrito una tercera de la lengua huaxteca, que incluiría un vocabulario. Alonso Urbano (hacia 1529-1608) aprendió, en los primeros años que estuvo en Nueva España (hacia 1557), las lenguas mexicana y otomí, y en ambas predicaba con mucha propiedad. Las dotes lingüísticas de Horacio Carochi quedaban de manifiesto en el hecho que, además del italiano, del español, del latín, del griego y del hebreo, también dominó el náhuatl y el otomí.

Dentro de la tradición andina, Domingo de Santo Tomás (1560, véase 1951, Prólogo al lector) manifiesta que «en quince años que estuvo en Perú había alcanzado conocimiento de la lengua general y que sería digno de reprehensión...que el talento que recibió de su señor lo había escondido (principalmente su don de lenguas [...]), luego comencé a tratar de reducir aquella lengua a arte». El historiador jesuita José de Acosta (1539-1600) se refiere a Alonso de Barzana (1528 - Cuzco 1596) ${ }^{4}$, de quien dice que «...les predicó, como una hora, en la lengua aymará, con grande atención y admiración de los indios [...].» (véase Acosta 1954:284). Además de dominar el quechua y el aimara, el padre Barzana igualmente conocía el puquina, y tenía conocimientos prácticos de otras nueve lenguas, en muchas de las cuales había escrito gramáticas, vocabularios y catecismos. En fin, para potenciar el aprendizaje de lenguas indígenas se habían fundado cátedras donde eran enseñados los sacerdotes que habían de adoctrinar a los indios. La primera cátedra de un idioma americano se instituyó en la Catedral de Lima en 1551; pero el verdadero impulso vino, sobre todo, a partir de los años setenta, cuando se decretó que los encargados de las parroquias y doctrinas debían conocer la lengua de sus feligreses. Para cumplir este requisito, Felipe II por cédula real de 1580 había ordenado que en las Universidades de Lima y México y en las ciudades donde hubiera audiencias territoriales se establecieran cátedras de «lengua general». En el mismo año será instituida la cátedra de lengua general (quechua) de los indios de Perú en la ciudad de Quito (cf. Torre 1962). Estos puestos, ejercidos por misioneros de prestigio, desataron la posibilidad de componer gramáticas vehiculares para la evangelización. Algunos de los autores de las artes de lenguas indígenas eran catedráticos de dichas lenguas en las respectivas áreas geográficas por donde se extendía su uso.

4. Barzana es quizá uno de los autores del famoso Anónimo (1584) o gramática y vocabulario del quechua y del aimara que acompañaba a la Doctrina Cristiana (1584), editados como resultado de los trabajos realizados a raíz de la celebración del Tercer Concilio Limense (1582-1583). 
Observábamos anteriormente que, al escribir sus gramáticas, los misioneros solían consultar e intentaban mejorar los trabajos que les precedían. Al mismo tiempo, la composición de estos tratados no fue el resultado de esfuerzos aislados, especialmente en lo concerniente a las lenguas generales. Existen datos internos reveladores (títulos de obras y uso de metatérminos como 'transición' en la tradición suramericana) que indican la continuidad gramatical. Los frailes encargados de las tareas lingüísticas leían no sólo las gramáticas y los vocabularios precedentes, sino que también solían trabajar en equipo en sus colegios y en sus propias escuelas de idiomas (véase Nágel 1994). El Imperial Colegio de Santa Cruz de Tlatelolco (al norte de la ciudad de México) había empezado a funcionar en 1533 y se inauguró solemnemente en 1536; en él fue maestro Andrés de Olmos ${ }^{5}$. Tepotzolán (también al norte de la Ciudad de México, hoy Museo Nacional del Virreinato) acogía un Colegio de Jesuitas, que fue planeado como una escuela de idiomas para los sacerdotes de su orden; Antonio del Rincón y su discípulo Horacio Carochi, ambos autores de sendas Artes mexicanas, residieron extensos periodos de sus vidas en el Colegio Jesuita de Tepotzolán.

Por lo que respecta a la tradición andina, en la misión de Juli (antiguamente capital de la zona de los Lagos), ubicada estratégicamente a orillas del lago Titicaca por la confluencia en esa zona de tres idiomas el quechua, el aimara y el puquina, existía una escuela que parecía consolidada ya en 1560 con los dominicos. En una carta del padre Juan Sebastián, provincial de los jesuitas del Perú, se dice que "los Padres de Juli tienen comenzado un libro de sermones y otro de ejemplos en la lengua aimara...y también tienen hecho un vocabulario...", lo que muestra el carácter compartido de sus actividades en 1595 (cf. Calvo 1997:324).

El papel del latín, de la gramática latina y del español son elementos importantes en la composición de gramáticas de lenguas indígenas por varias razones. Los misioneros europeos tenían conocimientos del latín -por ser lengua de cultura, de la ciencia y de la iglesia- y algunos del griego; en esa época, el latín era la puerta de entrada al estudio de la gramática, de la retórica y de la lógica. Habían aprendido a hablar y a escribir latín a través de las múltiples gramáticas prácticas que circulaban por Europa.

5. Para más información sobre el Colegio de Santa Cruz de Tlatelolco, incluidos los inventarios de su Biblioteca de 1572 y 1574, entre los que se encontraban los tratados gramaticales de Nebrija, el Dictionarium Calepino (Regio 1502), el Marciano Capella, el Catholicon (1268) de Joannes Balbus, un Vocabulario eclesiástico y otros textos de teología y de filosofía desde Aristóteles hasta fray Alonso de Veracruz, junto con obras antiguas de patrística y los clásicos grecolatinos, consúltense Mathes (1982) y Hernández y León-Portilla (1990). 
Los españoles lo hacían, sobre todo, con la ayuda de las Introductiones latinae (1481) de Antonio de Nebrija (1444-1532), obra que incluía definiciones nocionales de carácter general de las partes de la oración y de sus accidentes, y ponía determinado énfasis en el estudio de los elementos formales que correspondían a dichas nociones. Al mismo tiempo, se servían de los contenidos, estructura y metatérminos de esa obra para describir los idiomas indígenas y componer sus gramáticas ${ }^{6}$. La gramática latina de Nebrija era un tratado estándar en las universidades españolas. En las órdenes religiosas, esta obra era presentada como modelo para la elaboración de las lenguas indígenas (Aguirre 1983:207). Además, por los inventarios de los libros exportados de España a América, sabemos que, en el siglo XVI, se transportaron numerosas artes de Nebrija al Nuevo Continente. Por ejemplo, en 1583 y 1591 se llevaron 53 artes de Nebrija al Perú (cf. Leonard 1942 y 1953$)^{7}$.

La utilización del modelo gramatical de Nebrija tiene una dimensión utilitaria, pues es el modelo en el que se han formado los misioneros. Contiene una terminología que conocen los evangelizadores, a quienes van dirigidas fundamentalmente las gramáticas de los idiomas americanos. A los

6. La gramática latina de Nebrija representa el nuevo método que inició su andadura en Europa con Guarino de Verona (1370-1460) y que eliminaba de las gramáticas medievales, la terminología farragosa y logizante como causa eficiente y causa material, que utilizaban las gramáticas escolásticas para referirse al caso ablativo; terminología que confundía a los alumnos.

7. Durante la primera época de la colonización, en los dominios del Canadá francés se utilizó como prototipo de gramáticas los Rudimenta (1514) y los Commentarii grammatici (1538) de Johannes Despauterius (hacia 1460-1520), mientras que en Brasil se hizo popular, en el último cuarto del siglo XVI, De institutione grammatica libri tres (1572) de Manuel Álvarez (1526-1582) (cf. Zwartjes 2002:28). En 1579, es decir siete años después de la llegada de los jesuitas a Nueva España, el impresor Antonio Ricardo publicó, en México, los libros segundo y tercero de la gramática de Álvarez, dedicados, respectivamente, a la construcción o sintaxis de las partes de la oración y a la prosodia o estudio de la sílaba y el acento. Además de Nebrija, los jesuitas utilizaron a Álvarez hasta la edición en 1598 de la gramática del padre Juan Luis de la Cerda (1558-1643), comentador y adaptador de Nebrija; esta última obra fue una de las más populares y de las que con mayor frecuencia se imprimieron en Nueva Espańa. Los colonos indianos empleaban los libros fundamentalmente como un instrumento para mantenerse en contacto con los ambientes cultos de Europa. Por ejemplo, la cultura libresca desarrollada en Perú muestra la directa sintonía con las corrientes ideológicas europeas que por el mismo tiempo se divulgaban en el continente europeo. Aunque Nebrija era el autor más difundido en Hispanoamérica, el pensamiento de Santo Tomás se estudió con fuerza en la Hispanoamérica del siglo XVI, también Platón, la cultura latina y los trabajos más sugestivos del humanismo renacentista, así como el derecho canónico y civil, obras de literatura, de medicina y de veterinaria (cf. Hampe 1987). 
autores de éstas les interesa componer obras que se entiendan y aprendan con facilidad por sus correligionarios para que la conversión de indígenas avance lo más rápidamente posible. Con relación al quechua, Domingo de Santo Tomás (1560, véase 1951, Prólogo al lector) afirma que hay necesidad de un Arte para «animar a los que por falta de lengua están cobardes en la predicación del evangelio». Por razones de efectividad, a los misioneros les convenía analizar una lengua desconocida en el marco de otra conocida. En este sentido, fray Domingo (1560, véase 1951, Prólogo al lector) añade que "porque este arte [...] se hace para eclesiásticos que tienen noticia de la lengua latina, va conforme al arte de ésta» (cf. también Esparza 2003:88 con relación a una afirmación semejante hecha por Antonio del Rincón). Quizá por eso, los misioneros no se centren excesivamente en innovar o proponer terminología morfosintáctica nueva para hechos lingüísticos amplios en consonancia con las dinámicas propias de las lenguas indígenas, como hubieran deseado los gramáticos europeos de finales del siglo XVIII y posteriores, quienes operaban bajo otro esquema epistemológico y buscaban establecer nuevas tipologías lingüísticas. De ahí, que aquéllos se centren más en indagar las correspondencias de esos idiomas con el latín o las lenguas europeas.

Por ejemplo, en otomí, hay una categoría llamada «aspecto de localización», que indica la orientación del objeto y que aparece en composición con otras partes de la oración como el verbo, en lugar de expresarse formalmente mediante preposiciones y adverbios como en el latín o en otras lenguas europeas. Ahora bien, el Arte breve de la lengua otomi (1605; véase 1990) de Alonso Urbano sí tiene secciones con preposiciones y adverbios; pero en ellas presenta la marca de aspecto de localización peculiar al otomí, que él llama preposiciones o adverbios en composición, en lugar de lo que hoy denominaríamos categoría o morfema de localización. Así, Urbano (1990:51-54) señala que el adverbio local quequa 'aquî' aparece en composición con la forma (entiéndase alomorfo) -qua en la frase ti [yo] buaequa [estoy aquí]. También aduce ejemplos de la partícula cha 'aquí', que aparece antepuesta y pospuesta al verbo, como en cha ti buaey o mbuae ccan nichä, y de la partícula temporal nuya o quenya 'ahora' que en composición, con la forma (entiéndase alomorfo) ya, se pospone al verbo, como en ti xicca ya. Cuando Urbano ofrece equivalentes castellanos de sintagmas construidos en otomí con una marca de localización en los que la parte castellana contiene adverbios o preposiciones, lo que pretende decir en realidad es que los conceptos o nociones de localización de tipo universal que en otomí se expresan por partículas o marcas en composición con otras partes de la 
oración, en castellano se indican por medio de adverbios o preposiciones (cf. Zimmermann 1997a:126) ${ }^{8}$.

En fin, para el lector europeo distante de América, determinado número de análisis, descripciones gramaticales así como ejemplos parecen difíciles de entender en dichas gramáticas. Muchas veces, en sus ejemplos ilustrativos de alguna explicación gramatical, uno tiene la impresión de que los misioneros no identifican las raíces y las partículas de las lenguas indígenas lo suficiente para que los lectores que desconocen totalmente esas lenguas (como ocurría con los lingüistas europeos de siglos posteriores) entendieran las explicaciones; en el mejor de los casos habría que rebuscar en otras partes de sus gramáticas información para lograr dichas identificaciones que nos permitieran comprender satisfactoriamente sus explicaciones gramaticales. En parte, esto era así porque las gramáticas estaban escritas para los frailes que convivían con sus maestros de idiomas en los colegios y residencias, y que tenían contacto diario con los indios que hablaban esas lenguas.

Estos tratados servían, sobre todo, para reforzar el aprendizaje de las lenguas, que adquirían también en sus conversaciones diarias con los indios, les daban seguridad lingüística y les resolvían problemas gramaticales que les autorizaban a realizar las labores pastorales de forma más efectiva. $\mathrm{Al}$ contacto con los naturales, los misioneros ampliaban, corregían y pulían las artes y los vocabularios que les habían sido legados por sus antiguos correligionarios. Por ejemplo, después de la llegada de los jesuitas a Nueva España en 1572, en varios seminarios especiales, en los que instruían a los

8. Cf. también en este sentido el análisis del quechua en lo referente a lo que hoy denominamos sufijos del discurso (como, por ejemplo, Juan Pedropas mircurca 'Juan y Pedro comieron'), que Domingo de Santo Tomás (1560, véase 1951:122 y 142-148), el Anónimo (1586:38r-40r) y Diego González Holguín (1607, véase 1975:121v-123v y 141r$142 \mathrm{v})$ realizan, partiendo del concepto de conjunción, por sus equivalencias conceptuales con el castellano, aunque como todos esos sufijos o partículas no pertenecen a conjunciones, presentan una clase residual que Santo Tomás llama partículas, el Anónimo partículas diversas y González partículas finales. Tanto las que se traducen por conjunciones como las que tienen otros valores entran en composición con nombres y verbos. Así, la marca -pas que se traduce por ' $y$ ', los tres gramáticos citados la denominan conjunción copulativa, mientras que tanto - chu (indica pregunta o negación y no se traduce por una conjunción) como - cha (tiene un valor potencial o entrańa duda) se colocan en la clase residual de partículas. De todos modos, el hecho de que los misioneros no busquen una categoría nueva para describir este fenómeno en quechua se debe igualmente a que la separación entre conjunción y partícula para ellos no es tal dentro de la gramática universal, ya que la partícula es la parte de la oración que incluye todos las categorias significativas relativas (o sea, la modalidad) como la preposición, el adverbio, la conjunción y los afijos, que dependen de las categorias absolutas (Véase Sección 2). Aparte de que lo formal, en la gramática tradicional tiene menos peso que lo nocional (cf. Dedenbach-Salazar 1997:296-309). 
indios, se preparaban los de la Compañía para conocer a fondo el idioma vernáculo, y era con los muchachos indios con quienes lo aprendían. El primer año lo dedicaban a aprender alguna lengua antes de comenzar su labores pastorales (cf. Suárez 1992:260, 261 y 266).

El latín era importante para la composición de las gramáticas por lo que significaba dicha lengua y por cuanto que hasta la época de Nebrija, cuando se hablaba de gramática se quería decir la gramática latina, puesto que prácticamente éstas no existían para las lenguas romances. El texto bilingüe de las Introductiones Latinae (1481) publicado como Introducciones latinas contrapuesto el romance al latín (hacia 1488) tiene su trascendencia porque, además de convertirse en un tratado contrastivo latino-castellano, contiene como novedoso metaterminología gramatical impresa no sólo en latín sino también en castellano. La gramática latina bilingüe en su parte castellana debió de ser el esbozo o preludio de lo que ya probablemente en la mente de Nebrija, cuatro años más tarde, se convertiría en la Gramática de la lengua castellana (1492). En la primera de las dos obras, tenían los misioneros, en castellano, terminología gramatical latina, una lengua que consideraban ser poseedora de ciertas características universales (nomenclatura gramatical que continuará apareciendo en los tratados latinos en castellano para principiantes que saldrían a la luz en el transcurso del siglo XVI en Espańa y en las gramáticas castellanas para extranjeros publicadas en Europa en dicho siglo); y en la segunda había terminología castellana de una lengua vernácula que andaba suelta y que el propio Nebrija intenta reducir en artificio, tal como afirma (1492, Prólogo, véase 1980) «[...] acordé ante todas las otras cosas reducir en artificio nuestra lengua castellana [...] como vemos que se ha hecho con la griega y la latina, las cuales por haber estado debajo de arte [...] todavía quedan en una uniformidad». Esta segunda obra también serviría de ejemplo a los misioneros (si observamos el título que da al Libro

9. Por otro lado, no hay que olvidar que los indios desempeñaron tareas lingüísticas importantes no sólo como hombres lenguas o intérpretes, sino también como traductores y asesores lingüísticos. Los nativos que habían aprendido latín y romance les ayudaban a la traducción de la doctrina cristiana al idioma del lugar y a transferir frases o expresiones idiosincrásicas así como narraciones o historias indias al romance. Estos textos, que muchas veces iban incluidos en los libros de sus gramáticas, también constituían una fuente importante para la composición de sus vocabularios y ayudaban a adquirir cierta perfección en el uso de los idiomas nativos. Se imita en dicha metodología a la tradición renacentista europea, en la que después de haber aprendido los rudimentos de la gramática, se adquiría el buen uso de la lengua latina a través del estudio y la ejercitación basados en la lectura de las obras de los autores clásicos (cf. Breva 1994). En el Nuevo Continente, las obras que servían para aplicar dicha metodología eran los textos bilingües que recogían las hablas de los naturales, las historias indias de gran valor etnográfico y la doctrina cristiana. 
$\mathrm{V}$ «De las introducciones de la lengua castellana para los que de estraña lengua querran deprender») de cómo, con los cambios oportunos, debe ser, presentada de manera breve, una gramática para aprender una segunda lengua. La Gramática castellana, que tuvo poca repercusión en España al principio, ya que no se volvió a editar durante dos siglos, pudo ser útil a los misioneros, por cuanto que mostraba cómo una lengua distinta al latín se podía "reducir en artificio», tal como escribió en términos parecidos Domingo de Santo Tomás (1560, véase 1951, Prólogo al lector) al referirse a su esfuerzo «en querer reducir la lengua general de los reynos del Perú a arte, queriéndola encerrar debajo de preceptos y cánones» ${ }^{10}$.

\section{GRAMÁTICA UNIVERSAL Y ESTUDIO \\ DEL USO EN LOS IDIOMAS PARTICULARES}

El modelo teórico que subyace a la gramática tradicional con su énfasis en el componente lógico y nocional (la lengua mental universal) en contraposición con la forma o lo sensorial condiciona los tratados prácticos de enseńanza del latín. A pesar de todo, no cabe duda de que en las obras prácticas como la de Nebrija y en otras posteriores se ponía un mayor acento en el estudio de los elementos formales que en las gramáticas teóricas, sobre todo en el renacimiento por el interés de los humanistas en que la gramática práctica se convirtiera en una introducción al estudio del uso de los autores latinos.

Es indudable que en las gramáticas de Nebrija, como en toda gramática tradicional, las definiciones noéticas de los elementos de la oración, por ejemplo la definición de caso y de sus clases, tienen un gran peso. Esta nomenclatura de carácter nocional es útil para los misioneros, dado que los términos que incluye y sus definiciones son aplicables a las lenguas en general y, por tanto, a las lenguas indígenas. Serían metatérminos como nombre, verbo, verbo neutro, verbo activo o transitivo, caso, partícula, raíz y composición, este último tan útil para el análisis de las lenguas aglutinantes. Decir que el nominativo de verbos activos es el que hace la acción, es una definición noética general, mientras que afirmar que el nominativo aparece a la izquierda o a la derecha del verbo, como prefijo o sufijo, o como elemento independiente, es una definición formal que tiene una aplicación más limitada a una lengua particular. El valor de lo nocional y su precedencia

10. Para la proyección de Nebrija en algunas gramáticas amerindias, véanse Alvar 1992, Sarmiento 2000 y Galeote 2001; y Zwartjes 2000 para varios estudios sobre gramáticas misioneras en la tradición hispana. 
sobre la forma y su distribución viene dado por la creencia según la cual, dentro del marco nocional universal se explican mejor los rasgos particulares de las lenguas ${ }^{11}$.

De la lectura de las gramáticas manuscritas y publicadas de los misioneros, se colige que éstos analizaban, de manera consciente o inconsciente siguiendo el marco intelectual europeo, las lenguas con un modelo doctrinal de doble vertiente: la vertiente universal o racional y la vertiente del uso o manifestación de lo universal en los particularismos de cada lengua. Se trata del modelo logicista en el que se basa la gramática tradicional, que hunde sus raíces en la filosofía de Platón, de Aristóteles y de la gramática escolástica; esta última sufrió el influjo de la teoría tomista del conocimiento que separaba los niveles del mundo sensible y del mundo inteligible.

En Platón ya aparece una dualidad entre las 'Ideas' de las cosas, lo real, y las apariencias o lo diverso y cambiante en el mundo sensible. Por otro lado, en las Categorías (véase Samaranch 1964), Aristóteles estudia las diferentes maneras de existir las cosas en la realidad y señala que las categorías a las que se reducen todos los fenómenos del mundo son dos: absolutas y relativas. Esta realidad tiene su contrapartida en el lenguaje que, como reflejo de aquélla, posee igualmente categorías absolutas y relativas. A partir de Aristóteles, la tradición gramatical dispone de un término para denominar las categorías relativas del lenguaje. El areopagita las llama $\sigma u v \dot{\delta} \delta \sigma \mu o \mathrm{o}$ 'lazos o partículas relacionales' (Poética, Cap. 20 y Retórica, Libro IV, Caps. 5 y 12, en Samaranch 1964), mientras que Prisciano (siglo VI), en su Institutiones (Libro II: 15), las denomina syncategoremata 'elementos consignificantes'. En cuanto a las categorías absolutas, éstas se plasmaban en el lenguaje mediante el nombre y el verbo. Bajo este mismo marco doctrinal operaban también los gramáticos medievales de los siglos XIII y XIV, quienes aplicaban al estudio del lenguaje la teoría de los modi significandi que proponían los filósofos, o

11. Está claro que los misioneros, con la descripción de las diversas lenguas indígenas que poseían propiedades y reglas muy variadas, también contribuyeron a mostrar la riqueza de los sistemas de expresión particulares de las lenguas del mundo. Con relación al quechua, Domingo de Santo Tomás (1560, véase 1951, Cap. 2) destaca la importancia del uso y de su riqueza, «la principal razón en esto de los nombres y hablas es el uso, porque así se usa y lo usaron los primeros que hablaron la lengua y usan bien de ella [...] y lo mismo se dice de todas las demás maneras de hablar, verbos, tiempos o nombres que hay en esta lengua de más o de menos, no los hay o los hay en la latina o espańola. Porque, en cada lengua y términos de ella, lo principal consiste en el uso". El descubrimiento de todos estos nuevos sistemas de expresión y de su riqueza explica, en parte, el peso gradual que adquiere el estudio de la forma, lo sensorial, en los siglos posteriores en detrimento de lo nocional universal, de la nueva orientación hacia la búsqueda de tipologías universales sobre la base de elementos formales y semánticos al nivel de las lenguas particulares. 
modos cómo el entendimiento capta la realidad y forma conceptos. Como reflejo de dicha realidad, los modi significandi se plasmaban en el lenguaje y se dividían, como aquélla, en esenciales y accidentales. Los modistas entienden, pues, que los nombres y los verbos significan las entidades, lo absoluto (la permanencia y el flujo o devenir de las cosas, respectivamente) mientras que, por otro, las clases relativas o modos, que dependen o existen con relación a otras, se verbalizan en el lenguaje de varias maneras como pueden ser la conjunción, el adverbio y la preposición.

Igualmente nos permite un entendimiento más contextualizado de la lingüística misionera de la primera etapa hacer un breve repaso del pensamiento de Santo Tomás (hacia 1225-1274), en especial en lo tocante a su teoría del conocimiento y a su doctrina del verbo ${ }^{12}$, en las que se apoya la lingüística escolástica, ya que los modos de conocer se reflejan en los modos de significar o el lenguaje. En dicha teoría, el conocimiento intelectual o inteligible y el conocimiento sensible o sensorial tienen su contrapartida en el discurso humano en un verbo interior o lengua universal igual para toda la humanidad y en un verbo exterior o lenguas particulares que se caracterizan por su diversidad ${ }^{13}$.

12. Para su teoría del conocimiento, consúltese Summa Theologiae, Libro I, quaestio 85, art. 1, en Opera omnia 1980, Vol. 2. Sobre su doctrina del verbo, véanse De veritate, quaestio 4 (De verbo), art. 1, en Quaestio disputata I, Opera omnia 1980, Vol. 3; y De differentia verbi divini et humani, en Mandonnet 1927.

13. Se trata, en parte, de una reelaboración de la filosofía de Aristóteles y de sus afirmaciones en De la interpretación, Cap. 1 (en Samaranch 1964) y de la doctrina del verbo que desarrolla San Agustín (De Trinitate, Libro IX, Caps. 7 y 10, y Libro XV, Caps. 10 y 11, véase 1948) desde una perspectiva neoplatónica. En Santo Tomás, el conocimiento de la realidad (la res) implica la semejanza o universalidad de las imágenes (species intelligibiles expressae) o impresiones pasivas del entendimiento (conceptos del alma o verbo interior). Estos conceptos universales están en el lenguaje interior del alma, en el que contemplamos la verdadera realidad, el verdadero ser de las cosas. Ahora bien, para expresar el lenguaje interior, utilizamos los sentidos. Al nivel del conocimiento sensible, existe el verbo exterior (lo pensado y lo proferido por los sentidos), es decir las lenguas particulares cuya diversidad es patente en el uso. Lo pensado y lo proferido por los sentidos constituyen estructuras paralelas, mientras que no hay paralelismo entre el verbo interior y el verbo exterior. El verbo interior no pertenece a ninguna lengua, mientras que los idiomas de las naciones pertenecen al verbo de los sentidos corporales (cf. Arens 1980). El misionero Juan Bautista Lagunas (1574, véase 2002, Introducción) también parece referirse a estos dos niveles cuando, al parafrasear a Aristóteles sin mencionarlo, afirma que «Sirve pues la voz de ser la vestidura del pensamiento; y la escritura de cambio de la voz pronunciada [...]. Porque la misma manera [de entender], debe dar el depósito al lector que lee, [que]/ cuan[do] lo recibió de la voz». Aquí, alude al nivel sensorial que, ya sea leído o proferido, despierta en el entendimiento el mismo pensamiento. 
En el renacimiento, este marco teórico medieval pervive en algunos gramáticos logicistas y condiciona las gramáticas prácticas que se renuevan con relación a la descripción formal del latín y, por extensión, en lo referente a los primeros intentos para reducir las lenguas vernáculas «en artificio y razón». Algunos rasgos del marco doctrinal logicista que condiciona las gramáticas prácticas de esa época han quedado desdibujados para el lector actual por el distanciamiento en el tiempo, pero hay autores como el italiano Julio-César Escalígero (1484-1558) y el español Francisco Sánchez de las Brozas (1523-1601) que todavía trabajan, en sus tratados teóricos del latín, dentro de este marco, que percibía en la racionalidad (ratio) humana (como potencia capaz de entender la esencia de las cosas y como depósito de los conceptos pasivos o lo formado como resultado de la acción de entender) el origen de los rasgos o reglas universales que constituyen el fundamento o la causa, que sirve para explicar, de modo más adecuado, la variedad y el uso.

Siguiendo esta tradición medieval anterior, Escalígero (De causis linguae Latinae 1540, Libro III, Cap. 72; véase 1584) no sólo incluye la conjunción, el adverbio y la preposición como reflejo de las categorías relativas de la realidad, sino también los accidentes del nombre y del verbo como caso, género, número, tiempo, etc. (cf. Padley 1976:58-77). En este mismo sentido, Sánchez de las Brozas (Minerva seu de causis linguae Latinae 1587, Libro I, Cap. 2; consúltense 1986 y 1995) realiza una división tripartita de las partes de la oración en nombre, verbo y partícula, definiendo la partícula como dictio consignificans o elemento consignificante. Se trata, según afirma el salmantino, de una división universal que aparece en todas las lenguas. A la luz de esta concepción de partícula al nivel de la gramática universal, de la racionalidad, de las causas que subyacen a los usos de los idiomas particulares se comprenderá mejor lo que entienden los misioneros por partícula en el análisis de las lenguas indígenas. En el marco del modelo de doble vertiente, al nivel de los particularismos de las lenguas, existe la opinión de que las partes de la oración pueden variar en cada una de ellas.

Dentro de este mismo modelo, Escalígero (1584, Libro III, Cap. 74:161) realiza una distinción entre el caso y la declinación, utilizando el primer término para describir el fenómeno natural tal como lo entiende el conocimiento inteligible mientras que el segundo representa dicho fenómeno tal como se expresa formalmente en el lenguaje. Así, el tratadista italiano sustenta que el caso se inventó para distinguir las distintas maneras como entendemos las cosas y no la cosa en sí mientras cambia en la naturaleza. Por otro lado, el caso, prosigue, no es lo mismo que la declinación; pues, las declinaciones son las marcas derivativas (como ambulatio de ambulare) o flexivas, como cuando los nombres se reducen a la primera, segunda o 
tercera declinación. El caso no es la declinación porque el caso se reduce a esas marcas. Abundando sobre este mismo punto, Sánchez de las Brozas (1587, Libro I, Cap. 6) mantiene que todo nombre ha establecido seis partes o maneras de relacionarse las cosas entre sí en la naturaleza que define noéticamente como Escalígero, concluyendo que dicha división de casos es natural y, por tanto, "por necesidad lógica en todas las lenguas particulares (in omni idiomate) hay el mismo número de casos» ${ }^{14}$. Por eso, dentro de su modelo, para Sánchez de las Brozas, el griego no carece del caso ablativo, aunque no tenga marca formal de ablativo, ya que el griego expresa las funciones del ablativo por medio de las marcas formales del dativo como

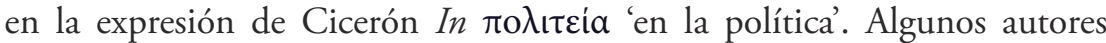
como Quintiliano y el propio Nebrija distinguían un séptimo caso en el que separaban el instrumento del ablativo. En Nebrija aparece como el caso efectivo (effectivus), que utilizarán algunos misioneros en sus descripciones.

No era mi intención aquí mostrar que ha habido una relación directa, sobre todo en la primera época, entre Escalígero y Sánchez de las Brozas, por un lado, y los misioneros por otro, sino más bien presentar el ambiente intelectual que flotaba, en el siglo XVI, en Europa y en Espańa en particular, donde resurgió con fuerza el pensamiento tomista, que se irradió desde Salamanca a otros centros universitarios; se trataba de una manera de pensar y de enfocar la gramática a la que los misioneros no debieron ser ajenos y que, hasta cierto punto, sirve para aclarar por qué éstos analizaban y enfocaban los tratamientos de las lenguas indígenas de la manera que lo hacían ${ }^{15}$.

Otro de los pilares sobre los que se asentaba la tradición gramatical tenía que ver con las teorías ligadas al origen del lenguaje y su evolución en la historia (racionalidad histórica). Se creía, basándose en el Génesis, Caps. 10 y 11 , que había existido una primera lengua y que la diversidad lingüística posterior fue el resultado de la dispersión de gentes a raíz de la confusión

14. El catedrático salmantino tiene la intuición de la existencia de un número de casos universales, pero no la capacidad de los lingüistas actuales para definir y perfilar el número aproximado de casos universales y de sus valores. En parte, soluciona este problema con el ablativo (una especie de cajón de sastre que incluye muchas de las cosas que no puede analizar con precisión); el ablativo es el caso de las causas (causa eficiente, causa material), del instrumento y de otros valores que se matizan por medio de las preposiciones.

15. Ecos de la doctrina del Brocense y de otros autores logicistas de los siglos XVI y XVII o de prestigiosos gramáticos que continúan sistematizando la lengua española se dejan sentir paulatinamente al otro lado del Atlántico. Las Artes mexicanas del seráfico Agustín de Vetancourt y de Carlos Tapia Zenteno de 1673 y 1753, respectivamente, son una buena muestra para percatarse del influjo de los gramáticos racionalistas como el Brocense en su pensamiento lingüístico. 
de las lenguas por el castigo de la torre de Babel ${ }^{16}$. Existía, pues, para aquéllos que opinaban que el lenguaje en su origen era natural, una lengua primordial que debía de ser perfecta en cuanto que reflejaba la racionalidad de la lengua interior que nos permitía conocer la ratio o esencia de las cosas de la realidad. A esta idea de una primera lengua se refiere Alonso de Molina (hacia 1514-1585) en el Prólogo al lector de su Vocabulario en lengua castellana y mexicana (1555, véase 2001), donde afirma, "Luego después del diluvio en toda la tierra no se hablaba más de una lengua, en la cual todos se trataban, comunicaban, y entendían [...]. Y ésta fue la confusión y división de las lenguas, para que donde antes era la lengua una, fuese la variedad y la diversidad de los lenguajes, que los unos no se entendiesen con los otros». Muchos pensadores, por lo menos desde Marco Fabio Quintiliano (hacia 35-95 d. de J.C), e incluso antes, creían que, con el paso del tiempo, la primera lengua se hace más figurada y se diversifica (cf. Breva 2001:20-21), aunque la base de sus principios racionales se mantienen, hasta cierto punto, en las demás ${ }^{17}$. Sin embargo, unas son más perfectas que otras y reflejan mejor la racionalidad o rasgos generales y regulares. Las lenguas antiguas, las lenguas clásicas -el latín y el griego- son más perfectas y han cambiado menos que otras, y, por tanto, guardan mejor los rasgos de esa racionalidad, es decir que, hasta cierto punto, formalizan mejor los rasgos racionales.

En el siglo XIII, algunos autores opinaban que el hebreo, el griego y el latín eran lenguas racionales, mientras que todas las demás eran 'bárbaras' Sin embargo, con la llegada del renacimiento, el fortalecimiento de los estados nacionales y el auge de la burguesía, al italiano, al español y a otras lenguas europeas se les prestigia y se les otorga un aura de respetabilidad ${ }^{18}$. El

16. Para el programa de actuación lingüística de los misioneros fundamentado en textos religiosos del Antiguo y Nuevo Testamento y en testimonios de la Tradición, consúltese Esparza 2003.

17. Esta postura está implícita en la Minerva seu de causis linguae Latinae (1587, Libro I, Cap. 1) de Sánchez de las Brozas, quien trató de conciliar la postura platónica del origen natural del lenguaje con la posición del origen convencional de éste defendida por Aristóteles y sus seguidores, puesto que como mantenían aquellos humanistas del renacimiento que intentaban dicha reconciliación, los primeros hombres debieron dar nombres a las cosas después de haber deliberado, por lo que la convención de Aristóteles sería una convención razonada. En su Arte, Lagunas (2002, Dedicatoria) parece referirse a la racionalidad histórica, la cual nos ayudaría a explicar lo diverso, cuando afirma que "Ante todo debe [sic] buscarse los principios de las cosas: para que se pueda tener un conocimiento más pleno de ellas. Pues entonces más fácilmente podrá declararse la razón de la causa [causae ratio], si se aprende cerca del origen"

18. En España, el licenciado Cristóbal de Villalón (hacia 1505-hacia 1558) se quejaba, en el Proemio al lector de su Gramática castellana (1558), de que solamente se considerasen «las 
proyecto humanista de elevar las lenguas vulgares y bárbaras a la condición de lenguas de cultura se transplanta y es asumido por los misioneros gramáticos del Nuevo Mundo, sobre todo, por el interés que tenían de que se predicara a los naturales en sus propias lenguas y avanzara así la evangelización con mayor celeridad, en contraposición con los pronunciamientos de algunos edictos y cédulas reales para que se hiciera en castellano por el deseo de la Corona de promover, al mismo tiempo, la espańolización y la integración política y social de los indios (cf. Suárez 1992:249).

Dentro de este mismo contexto del lenguaje y de su desarrollo en la historia, en su Arte de la lengua mexicana (1547), Andrés de Olmos escribe:

Primeramente se porná la conjugación, no como en la gramática [entiéndase gramática latina], sino como la lengua lo pide y demanda, porque algunas maneras de decir que nosotros tenemos en nuestra lengua, o en la latina, ésta no las tiene y paréceme que será confusión, por no salir de la conjugación del latín, poner algunos romances en tiempos que no les pueden cuadrar, como parecerá en la conjugación de los verbos [véase 1993:61].

Con ello, Olmos sostiene que la lengua latina y la castellana mantienen mayor racionalidad y perfección en la expresión de los valores temporales, acercándose más a lo que debería ser esa lengua natural. De ahí, que "ésta no las tiene» indica una carencia y un juicio de valor motivado por su marco doctrinal. Por todo ello, Olmos se excusa, dado que, sin romper la tradición misionera, presenta el complejo sistema de tiempos y modos latinos o castellanos y las formas equivalentes en náhuatl que, aunque muchas veces no existen formalmente, él se esfuerza en proporcionar, aportando la correspondencia o traducción más apropiada o cercana en dicha lengua. Por ejemplo, afirma (1993:62) que el futuro perfecto «aure guardado» no lo tiene el náhuatl y que lo suple por el pretérito perfecto. Lo que sí hace distinto Olmos es romper el orden en el que normalmente se explica la conjugación en la gramática, puesto que el orden que propone es más pedagógico y se adecua más al sistema de dicha lengua:

Y porque la brevedad ayuda mucho a la memoria, quien quisiera fácilmente aprender la conjugación tenga este aviso: que fuera del indicativo, en todos los otros modos no hay sino dos tiempos diferentes, que es el presente del imperativo

lenguas Hebrea, Griega, y Latina de más perfección», pues la lengua castellana había sido ya sujetada «a arte con reglas y leyes». 
que sirve también para los presentes del optativo y subjuntivo y el pretérito imperfecto del optativo que sirve para perfecto y pluscuamperfecto del mismo modo [...]. De manera que sabido el indicativo y presente de imperativo y pretérito imperfecto del optativo, está sabida toda la conjugación así de activa como de pasiva [1993:72].

Son los motivos prácticos los que le llevan a romper el orden con el que tradicionalmente se exponían los tiempos y los modos, puesto que comienza con los que tenían marcas distintivas en náhuatl y continúa con los que no las poseían ni existían, y que, por tanto, había que traducir por tiempos y modos ya existentes o con la ayuda de paráfrasis.

Para los evangelizadores, pues, el latín y hasta cierto punto el castellano, son lenguas que conservan más rasgos universales que las lenguas indígenas. Hasta el mismo siglo XVIII y principios del XIX algunos pensadores opinaban que las lenguas flexivas eran más antiguas y más perfectas que otros tipos de lenguas. Pero, al mismo tiempo, el latín y el castellano se consideran lenguas particulares con sus usos específicos. Hernández (1997:51) parece percibir el matiz que distinguen los misioneros entre lo general y lo particular de cada lengua al señalar que «Ciertamente en muchas ocasiones la gramática latina se concibe como discurso gramatical genérico [...]. La distinción entre gramática y arte tendría justamente que ver con la distinción entre discurso gramatical genérico y descripción de una lengua con interés puramente instrumental» ${ }^{19}$. Sin embargo, Hernández, a

19. Hernández está en lo cierto cuando afirma que se da una distinción entre gramática y arte en los misioneros. En la tradición europea, ésta distinción es más patente cuando se leen autores teóricos como Escalígero y Sánchez de las Brozas, quienes distinguen la gramática como ciencia o conocimiento de lo racional, por un lado, y, por otro, la gramática como ciencia o disciplina del bien hablar basado en el estudio del uso de los autores, o como método o arte que se ocupa de los preceptos del uso. La gramática como ciencia o estudio de los principios del lenguaje se ocupa de los aspectos universales, racionales, las causas del uso, mientras que la gramática como arte se centra en lo sistemático y no sistemático dentro de los particularismos de los usos de las lenguas. Aunque estas distinciones no se explicitan claramente ni en las Institutiones Latinae de Nebrija, ni en su Gramática castellana, ni en las obras de los misioneros, en las que incluso hallamos cierta libertad en la utilización, muchas veces indistinta, de los términos gramática y arte. No obstante, sí parece más claro por sus análisis que los autores de esa época operan bajo el modelo de doble vertiente, el universal y el del uso. Domingo de Santo Tomás (1951, Prólogo al lector) sostiene que arte es dar reglas "del modo de hablar de cualquier lengua». Así, arte sería como describir los particularismos de las lenguas, y continúa afirmando «este negocio... requería más erudición y conocimiento de la significación y propiedad de los términos de ella (que es la materia del arte)». En la tradición gramatical de la región andina, el primer trabajo impreso del quechua de Domingo de Santo Tomás lleva por título Grammatica o arte de la lengua... (1560) y lo mismo ocurre 
mi juicio, desconoce, en parte, el modelo epistemológico bajo el que operan los religiosos al añadir : «Pero el misionero no es absolutamente consecuente con esta distinción implícitamente apuntada en su texto, porque el discurso gramatical genérico no deja de sentirse al mismo tiempo como propio de una lengua concreta (la latina) que, para determinados efectos, puede ponerse a pie de igualdad con las lenguas descritas». En realidad, para el misionero el que el latín se conciba como discurso gramatical genérico y particular a la vez, no es una incoherencia o inconsecuencia, sino el resultado de su modelo teórico con dos niveles: el lógico o racional más universal y el nivel del uso con los particularismos de las lenguas. Por motivos prácticos de enseñanza de lenguas, al misionero le conviene contrastar los particularismos del uso latino o del uso castellano con el de las lenguas indígenas, contraste de usos que le permitía desarrollar su labor evangélica con eficacia y traducir la Doctrina Christiana a dichas lenguas con mayor efectividad. Ahora bien, por otro lado, la lengua latina, una lengua que cree más perfecta, más completa y que se acercaba más a las características de la lengua primordial, mantiene más rasgos de la racionalidad universal y, por tanto, hay que explicar aquéllas a partir de ésta.

A la luz de la reconstrucción anterior del modelo teórico de los misioneros, el lector actual puede comprender mejor el fragmento extraído de la Gramática o arte (1560) del quechua (véase 1951, Prólogo al rey don Felipe) de Domingo de Santo Tomás:

Si viere por esta arte [...] la gran abundancia de vocablos [...] las diversas maneras de hablar [...]. Y, brevemente, en muchas cosas y maneras de hablar tan conforme a la latina y espańola; y en el arte y artificio de ella, que no paresce sino que fue un pronóstico que españoles la avían de posseer. Lengua pues, S.M., tan polida y abundante, regulada y encerrada debajo de reglas y preceptos de la latina como ésta (como consta en esta arte) no bárbara, que quiere decir (según Quintiliano, y los demás latinos) llena de barbarismos y defectos, sin modos, tiempos, ni casos, ni orden, ni regla, ni concierto, sino pulida y delicada [...], pues según el philosopho [o sea, Aristóteles] en muchos lugares no ay cosa en que más se conozca el ingenio del hombre que en la palabra y en el lenguaje que usa, que es el parto del entendimiento del hombre.

con las obras de Ludovico Bertonio sobre el aimara Arte y gramática muy copiosa... (1603) y de Diego Holguín sobre el quechua Gramática y arte nueva... (1607). El mismo Cristóbal de Villalón también emplea ambos términos en el título completo de su Gramática castellana publicada en Amberes, en 1558. 
En él, el dominico, entre otras cosas, se refiere explícitamente al modelo dicotómico bajo el que actuaban: el nivel de los particularismos de las distintas lenguas y el nivel del entendimiento, que es una facultad del alma cuyas operaciones forman los conceptos universales, el lenguaje mental, racional, los principios invariables que subyacen a las lenguas particulares.

\section{EL ANÁLISIS DE LOS DATOS LINGÜÍSTICOS A LA LUZ DEL MARCO INTELECTUAL DE LA ÉPOCA}

Los misioneros actúan dentro del marco intelectual descrito aquí, marco que está implícito en sus obras y que no es necesario explicar, ya que estaba claro para sus coetáneos. Sin embargo, el paso del tiempo lo ha ido desdibujando para los lectores de épocas posteriores. Observábamos anteriormente que, en el contexto europeo de donde procedían los misioneros, se opinaba que el latín gozaba de mayor prestigio que otras lenguas y que se asemejaba más al orden natural o a lo que debieron ser las primeras lenguas. En el análisis del latín, las partes de la oración son ocho: nombre, verbo, participio, pronombre, preposición, adverbio, interjección y conjunción, según Nebrija (Introductiones Latinae 1481, a.i.). En realidad, al nivel de las lenguas particulares las partes de la oración se considera que son una clase abierta, según da a entender Nebrija en la Gramática castellana, pues, en su propias palabras (1980:132), con relación al griego «los latinos no tienen artículo, más distinguen la preposición del adverbio» y el castellano "tiene diez partes de la oración». Esta apreciación da libertad a los misioneros para dividir las partes de la oración de las lenguas indígenas según sus propios particularismos, aunque luego intentarán explicar o resolver esos particularismos a partir del esquema latino por razones prácticas y de posicionamientos teóricos.

En su Arte y vocabulario de la lengua guarani (1640), Antonio Ruiz de Montoya utiliza el modelo de la gramática latina y, al final del preludio de su obra, afirma (véase 1993) "Tiene esta lengua las ocho partes de la Oración, nombre, pronombre, verbo, participio, posposición, adverbio, interjección, conjunción", donde introduce un cambio necesario en guaraní al sustituir preposición por posposición. Ahora bien, hay que suponer que la categoría "posposición» no corresponde a lo que Ruiz de Montoya consideraría parte de la oración natural. Por eso, en el primer párrafo del Cap. 7 «De las Posposiciones», después de enumerarlas, señala "Las cuales se irán explicando y reduciendo a las preposiciones Latinas. Llámanse éstas posposiciones porque se posponen» (pág. 71). Ruiz de Montoya piensa que 
la gramática latina posee un sistema general que le permite describir gran parte de los mecanismos gramaticales de esa lengua indígena ${ }^{20}$.

Desde Aristóteles, al nivel lógico, las lenguas tienen tres partes de la oración, aunque luego en su verbalización o desarrollo particular tienen un número que puede variar. Así, las ocho partes del latín o las posibles partes de las lenguas particulares se reducen a tres al nivel universal: nombre, verbo y partícula, como vimos anteriormente. Si tenemos en cuenta esta doble división de las partes de la oración, se aclaran algunos análisis de los misioneros. En las descripciones de la época colonial, a menudo, los misioneros emplean el término partícula en sentido amplio para englobar los elementos consignificativos o relacionales como la preposición, el adverbio, la conjunción y los afijos que dependen de otros elementos como advertíamos en el modelo lingüístico expuesto por algunos gramáticos teóricos en Europa.

En su Arte de la lengua mexicana (1547), Andrés de Olmos utiliza el término partícula para denominar los elementos relacionales del náhuatl. Por eso, agrupa en torno a esta categoría a los que en la nomenclatura moderna llamaríamos afijos derivativos como los diminutivos, a los afijos flexivos como el caso, el número y los tiempos verbales, y a las partes indeclinables de la oración como las preposiciones, los adverbios y las conjunciones, ocurran en composición con otras partes de la oración o como elementos separados. Esta clasificación ha sido malinterpretada por algunos críticos modernos que ven en ella opacidad y ambigüedad ${ }^{21}$. Sin embargo, para Olmos y los hombres de su tiempo quedaba claro que partícula incluía todo aquello que únicamente existía con relación a otras cosas en el sentido Aristotélico, y de la cual se excluían las categorías independientes, o sea las

20. Dado que al nivel de los particularismos de las lenguas, se entiende que las partes de la oración son una clase abierta, en su Arte en la lengua michuacana (1574) Juan Bautista Lagunas (murió en 1604) llama interposiciones a las partículas entre el elemento inicial de esta lengua aglutinante (que denomina indistintamente preposición verbal, raíz o partícula) y el ni del infinitivo. Las interposiciones con un promedio de cinco a siete por unidad lingüística son por lo general elementos derivativos y flexivos. En michoacano, interposición es un término que describe la posición formal de dicha partícula. Es más Lagunas se percata de que las interposiciones son una clase importante y abundante en el idioma michoacano. Por eso, se formula la pregunta (2002:240) «Empero a las otras segundas [partículas], y a las demás que siempre se interponen entre estas inseparables preposiciones o raíces de los verbos, y el ni que termina el infinitivo. ¿Por qué razón no serán partes particulares [énfasis mío] de la oración, y se llamarán interposiciones?».

21. Una interpretación del término partícula en las gramáticas misioneras, que coincide con la que mantenemos aquí, es la realizada por Suárez (1992:224), si bien Suárez no reconstruye los antecedentes históricos y filosóficos que llevan a los religiosos a emplear dicho término en sentido amplio y genérico. 
raíces de los nombres y de los verbos, así como los pronombres primitivos y posiblemente los pronombres derivativos, éstos últimos eran los que se juntaban o aparecían en composición con verbos y nombres.

Veamos algunos ejemplos de cómo emplea Olmos la palabra partícula en su obra. En términos actuales, el náhuatl es una lengua que no tiene marcas de caso, en la que la relación sintáctica de los argumentos, como sujeto u objeto, con el verbo no se marca en el mismo sintagma nominal sino en el verbo del que dependen; se trata pues de lo que hoy en día llamamos clasificadores. Así, Olmos (1993, Segunda Parte, Cap. 7, sobre «Los verbos activos y algunas partículas que se juntan con ellos») muestra que hay elementos que incorporados al verbo marcan la naturaleza inanimada o animada de un argumento indefinido (que puede estar presente o sobrentendido), al señalar «que esta partícula tla denota que la acción del verbo a quien se junta puede generalmente convenir o puede pasar a cosas inanimadas nitlatlaçotla» (donde ni es 'yo', tla 'algo indefinido o cosa inanimada objeto' y tlaçotla 'presente de indicativo de amar'), que el franciscano traduce por 'yo amo algo [sobrentendido]'. Olmos prosigue «Esta partícula te denota que la acción del verbo pasa en cosas animadas y por la mayor parte se dice de cosas racionales»; el ejemplo que encontramos en su Arte es nitetlaçotla, que traduce por 'yo amo [alguno indefinido o cosa animada]'. Asimismo, Olmos se refiere a los elementos que incorporados al verbo marcan la concordancia de persona, caso y número de los argumentos, afirmando que «De las partículas que denotan cual ha de ser la persona paciente-denotan singular o plural $c$, qui, quin». Se entiende que las dos primeras partículas marcan el singular de tercera persona y la última el plural de tercera persona, como en nictlaçotla yn Iuan (ni 'yo', c 'marca de transitividad', tlaçotla 'presente de indicativo', yn 'artículo' y Iuan 'Juan'), que interpreta como 'yo amo a Juan'. En resumen, manifiesta que mientras que $c$, qui, y quin son partículas que muestran que un verbo es activo cuando lleva tras de sí persona que padece expresa, la te y la tla son partículas que señalan que un verbo es activo cuando se trata de un objeto indefinido animado (te) o inanimado ( $t$ la) expreso o «sub intelecto [sic]». Al hablar de partícula más que de pronombre, Olmos insiste aquí en el carácter relacional de dichos elementos ${ }^{22}$.

En el punto que hemos tratado, el franciscano encuentra diferencias radicales con el latín, que se afana en destacar (1993, Segunda Parte, Cap. 7) «y esto postrero tiene más dificultad, porque en la lengua latina no se hallan

22. Más tarde, en sus Artes respectivas de 1595 y 1645, Antonio del Rincón y Horacio Carochi llaman semipronombres a esos afijos verbales o clasificadores de cosas animadas o inanimadas indefinidas o de persona, que indican la clase de relación existente entre los argumentos y los verbos concomitantes. 
partículas así incorporadas o juntas con el verbo, las cuales denotan la persona que padece» y describe con cierta agudeza los particularismos del náhuatl:

Es de notar que ningún verbo activo puede estar sin alguna partícula de éstas, salvo cuando el verbo está compuesto con nombre y tiene incorporada en sí la persona que padece. Ejemplo: nipettlachiua yo hago petates [ $n i$ 'yo, pettla 'petates, chiva 'presente de indicativo de hacer']; y también cuando se junta el verbo con algún pronombre que tiene lugar de persona paciente, porque entonces bien estará sin las dichas partículas, ninotlaçotla, yo me amo [ $n i$ 'yo', no 'me'], timechtlaçotla 'tú te amas' [ $t i$ 'tú', mech 'te'].

Estos análisis que mostraban indirectamente las dinámicas propias de las lenguas indígenas van a contribuir paulatinamente y a medida que pasen los ańos a romper el marco epistemológico bajo el que operaban los misioneros, sobre todo, a medida que se obtengan descripciones de un mayor número de lenguas del mundo y el interés gramatical pase no sólo de estar enfocado hacia la evangelización sino también a una mayor preocupación por lo puramente lingüístico. Este cambio se verá favorecido igualmente por las ventajas que ofrece el hecho de que con el transcurso del tiempo sea posible comparar entre sí lenguas de diversas regiones del mundo, como ocurrirá en la Europa del siglo XVIII.

Aunque partícula se emplee en el sentido aristotélico de elemento relacional, este metatérmino no es unívoco. En su Arte en la lengua michuacana (1574), Juan Bautista Lagunas llega prácticamente a equiparar partícula (en latín significa partecilla o parte pequeña como traduce Nebrija) con lo que hoy entendemos por morfema ${ }^{23}$, puesto que en la expresión verbal irhah/

23. Cf. en este sentido la afirmación «El uso variado de la palabra partícula en la obra de Gilberti abarca, como hemos visto, cualquier parte de la palabra; se refiere a raices como en el caso de las raíces verbales cuyo significado es la forma o posición de los objetos; se refiere a los morfemas derivacionales, así como a los morfemas de flexión» de Monzón (1997:137) con relación a la primera gramática que se imprimió en el Nuevo Mundo, el Arte de la lengua tarasca o de Michoacan (1558) de Maturino Gilberti (1498-1585), fraile seráfico de origen francés y educado en la Universidad de Toulouse. Por esa misma época, Domingo de Santo Tomás, en su Gramática o arte (1560) del quechua, también emplea dictio en sentido amplio con el valor de lo que hoy entenderíamos por morfema. Así, para este dominico dicho término es equivalente o intercambiable con metatérminos como partícula y artículo (recuérdese su procedencia latina articulus 'parte, trozo o fragmento'). A los sufijos que marcan el caso como - $p i$ 'en' (yayánc/pi 'en el señor') las llama dicciones, partículas o artículos. Partícula también le sirve para denominar todo tipo de sufijos derivativos, flexivos y partículas independientes. En fin, a la forma noca 'yo', que es un pronombre primitivo o independiente, la llama igualmente dictio (véase 1951, Caps. 2 y 3 sobre el nombre y el pronombre). 
tsi/ta/ni (forma redonda de cosa/encima de algo/ hacer a ello que se ponga o poner/ marca del infinitivo; es decir 'poner alguna cosa redonda encima de algo'), al elemento o clasificador de forma irhah lo llama preposición verbal, a veces raíz y otras partícula, a las marcas tsi y ta (tsi es un clasificador locativo y ta un causativo) las denomina interposiciones o partículas y a la marca $n i$ del infinitivo la llama también partícula (cf. Lagunas 2002:231-237 y 240). Según esto, Lagunas denomina partícula a todas las unidades mínimas de significado que se encuentran en la forma verbal ${ }^{24}$. De acuerdo con esto, la noción de morfema aparece en estado larval en la tradición misionera de la época temprana. Los misioneros necesitaban un término de trabajo amplio para describir lenguas polisintéticas y lo encuentran en partícula y dicción (véase nota 23). Ahora bien, por lo general, ellos no tenían como prioridad

24. Una pregunta que nos podemos formular es por qué Lagunas llama de maneras tan variadas esos elementos que marcan en el verbo la forma de los objetos (es decir, las marcas o clasificadores de forma como ihra para cosas redondas, echu para cosas anchas como papel, tabla, tortillas o ycha para cosas largas como palo), objetos que cuando se explicitan aparecen como argumentos alrededor del verbo. Siguiendo de cerca a Nebrija (en sus Introducciones latinas 1488 [véase 1996:39] y en su Gramática catellana 1492 [véase 1980:196]), Lagunas (1574, Tercera Parte, Cap. 6:240 [véase 2002]) señala "y así llamaremos a las primeras partículas, y, otras como ellas preposiciones verbales inseparables como en latín Am, Com, $D i s, D i, R e$, Se, que nunca se hallan fuera de composición", dando ejemplos como disiungo o secerno. Con ello quiere decir que dichos elementos iniciales del michoacano son semejantes a los prefijos latinos dis- o se-, que son partículas o preposiciones verbales que indican la manera de poner las cosas, pues iungo es 'poner junto o unir' y dis-iungo es 'poner por separado o desunir', mientras que cerno tiene un sentido originario raro, pero se-cerno es 'poner por separado'. Conjeturo que el hecho de que a estos clasificadores o marcas de concordancia que indican la forma del argumento en el verbo les llame igualmente raíces debe estar motivado por el hecho de que cuando no aparecen en composición sino como argumentos fuera del verbo son prácticamente iguales formalmente excepto por el pequeño afijo nominalizador que se les ańade; así, el mismo Lagunas (Parte Tercera, Cap. 4) afirma que «tomando cualquiera de estas partículas, las cuales cierto en esta lengua son preposiciones verbales y sobre cada cual ańadiendo qua, sacará y formarse ha la tal cosa significativa” como yrhaqua 'cosa redonda', ichaqua 'cosa larga' y echuqua 'cosa ancha' ". Aunque guiado por la distribución formal de elementos aglutinados en el verbo, llame interposición a la segunda partícula y no busque un metatérmino común para ambos clasificadores (pues ambos marcan la concordancia del verbo con sus argumentos, la primera en lo tocante a la forma del objeto y la segunda en lo referente al lugar donde se pone éste), Lagunas sí describe el clasificador espacial de forma adecuada en la Tercera Parte, Cap. 5, titulado "Las partículas o interposiciones que sirven a los lugares comunes, a donde se ha de poner tales cosas». Así, explica que tsi es para encima generalmente o la cabeza como en irhahtsitani 'poner cosa redonda encima de algo', rhu para cosa delantera o frontera como en yrharusitani 'poner cosa redonda al frente de algo', $n$ di para rincón, o esquina, o orejas como en yranditani 'poner cosa redonda en tales partes' y chu para debajo de algo generalmente o las partes bajas como en ihrahchutani 'poner cosa redonda debajo de algo'. 
proponer o buscar terminología descriptiva nueva y precisa como hubiera sido el caso de un lingüista en la actualidad. Su finalidad principal era, sobre todo, servirse de términos que permitieran a los eventuales lectores comprender sus descripciones, más que prestar excesiva atención a si habían quedado o no bien definidos.

A algunos críticos modernos les sorprende, que los misioneros denominen partícula a lo que hoy entendemos por afijos, pero también les llama la atención el uso que hacen de los términos caso y declinación, dado que encuentran en su utilización ciertas contradicciones por parte de éstos, por ejemplo el francés Rémi Siméon y el conde de la Viñaza en el siglo XIX. Como gramático práctico que aplica los conceptos lógicos y nocionales de tipo general a la descripción de dos lenguas concretas, el latín y el castellano, Nebrija entra más en el detalle de la complejidad de los datos lingüísticos con relación a los términos caso y declinación que, por ejemplo, teóricos como Escalígero y Sánchez de las Brozas.

En su Gramática de la lengua castellana (1492) y en sus Introducciones latinas (1488), Nebrija sigue la tradición gramatical entendiendo por caso lo nocional, o sea que caso es la función que desempeña el nombre en la oración. Así, «El primero llaman los latinos nominativo, porque por él se nombran las cosas y se pone quien alguna cosa hace» $\mathrm{y}$ "El cuarto llaman acusativo, porque en tal caso ponemos a quien acusamos y generalmente a quien padece por algún verbo» (véanse 1980:177 y 1996:105). En cuanto a la relación entre caso y preposición, el catedrático de Alcalá señala, en lo que al latín se refiere, que algunos casos, a veces, se pueden regir del verbo, no directamente, sino por fuerza de la preposición, como el genitivo, el acusativo y el ablativo (1996:38 y 119-121). Puesto que la plasmación o manifestación formal del caso en castellano difiere del latín, su descripción de dichos rasgos formales en ambas lenguas proporciona amplitud de análisis a los misioneros cuando examinan dicho fenómeno en las lenguas indígenas. Respecto al castellano, indica que «la significación [el valor nocional] de los casos [la lengua castellana] distingue por preposiciones», el genitivo lleva de, el dativo $a$, el acusativo la preposición $a$ o sin ella y el vocativo el adverbio $o$ (1980:176-177). En fin, en el Capítulo 15, donde trata sobre la preposición, sustenta que el caso es uno de los accidentes de la preposición, pues las preposiciones rigen dos casos, así ante, cerca, después se juntan al genitivo (ante de medio día, cerca de la ciudad, después de medio día) y contra, entre, por se unen al acusativo (contra los enemigos, entre todos, por la calle) destacando que aquí «sirven [...] las preposiciones para demostrar la diversidad de la significación de los casos» (1980:195-196). 
En Nebrija, la definición del término declinación como elemento formal también encaja perfectamente dentro del marco doctrinal de la tradición gramatical. Es decir, que «Declinación es la diversidad de la voz la cual se halla cerca del fin» (1996:106), definición que le permite afirmar de manera congruente que "el verbo se declina con modos \& tiempos sin caso" (1996:109). Además, en las gramáticas prácticas del latín, se colocaba bajo el epígrafe de declinaciones de los nombres las cinco clases de declinaciones o terminaciones que Nebrija presenta en el Libro Primero de sus Introducciones latinas. En fin, con relación al castellano, señala que «Declinación del nombre no tiene la lengua castellana, salvo del número de uno al número de muchos»; es decir que hay tres declinaciones, las de los nombres que acaban en $-o$, en $-a$, y en consonante, de las cuales hacen el plural en $-s$, las dos primeras como tierraltierras, cielolcielos, y en -es, la tercera como ciudadl ciudades (1980:176).

Una vez hemos aclarado los conceptos de caso y declinación en el marco intelectual europeo, pasemos ahora a examinar las descripciones de los misioneros en este punto y algunos juicios emitidos por la crítica moderna al respeto. Rodrigues (1997:380-381) expone que Alonso de Molina, en Arte de la lengua mexicana y castellana (1571, véase 1945), después de afirmar que «en esa lengua ningún nombre varía ni declina por casos, así como la latina [6v]», presenta el singular y el plural de la palabra dios diciendo «declínanse de esta manera: Nominativo, teutl; genitivo, teutl; dativo, teutl; acusativo, teutl; ablativo, teutl; plural, nominativo, teteu; genitivo, teteu; dativo, teteu; acusativo, teteu; ablativo, teteu» (1945:7). Rodrigues observa en estas frases una contradicción. Sin embargo, lo que, en realidad, indica Molina es, por una parte, que los valores nocionales de caso no llevan ninguna marca de declinación en náhuatl y, por otra, que el valor nocional de plural lleva declinación o expresión formal con relación al singular (es decir, que la declinación del nombre es por el número de uno y de muchos); o sea que el singular teutl se convierte en teteu en plural, explicación que es importante para los religiosos que están aprendiendo los rudimentos del náhuat ${ }^{25}$. Siguiendo la tradición gramatical, aunque el nombre no se declina por

25. Sobre este mismo punto y también con relación al náhuatl, Andrés de Olmos (1993, Primera Parte, Cap. 7:31) manifiesta que los sustantivos primitivos no tienen declinaciones, pero hacen diferencia entre el singular y el plural. Y Horacio Carochi, en Arte de la lengua mexicana con la declaración de los adverbios de ella (1645, véase 1983), explica que el nombre no tiene variación de casos, sino de números, singular y plural, distinguiendo hasta un total de cuatro declinaciones de número según las terminaciones del plural; en la primera declinación, por ejemplo, si el singular acaba en $t l$, el nombre toma - me en plural, como en icheatl 'oveja', plural icheame (1983:3v-6v). 
casos, Molina presenta el paradigma del nombre por motivos pedagógicos, el cual muestra que el nombre no registra diferencias por casos, pero que el número sí lleva declinaciones o terminaciones en esa lengua. Se trata de un paradigma nocional que es importante para los misioneros que están aprendiendo esa lengua.

Una contradicción parecida advierte Monzón (1997:141-143) en la descripción de los casos que realizan Maturino Gilberti y Juan Bautista Lagunas en sus Artes respectivas (1558 y 1574) de la lengua michoacana (cf. asimismo Hernández de León 2003:15-16 y 19-20, en lo tocante a supuestas incoherencias en el análisis del caso y de la declinación en Antonio del Rincón y Maturino Gilberti) ${ }^{26}$. Es más, Monzón seńala que «tanto él [Lagunas] como Gilberti no logran romper con el marco teóricometodológico que constituye la gramática latina». A mi juicio, es desear mucho que en el lugar, en la época, en las condiciones, en el contexto epistemológico en el que se encontraban y con la finalidad que perseguían, éstos quisieran, intentaran o lograran romper el marco teórico-metodológico bajo el que operaban. Tanto Gilberti como Lagunas reconocen la inexistencia de varios casos. Pero, después de haber admitido dicha ausencia de varios casos en michoacano, lo que sorprende a Monzón (1997:141-142) es que, «ambos presenten el mismo paradigma de la declinación, paradigma que no tiene en cuenta» dicha afirmación (Gilberti 1558, Primera Parte, 12r, véase 1987; y Lagunas 1574:58, consúltese 2002), pues Lagunas, por ejemplo, declina la palabra angel en siete $\operatorname{casos}^{27}$ :

\begin{tabular}{|c|c|c|}
\hline Nominativo & Angel & El Angel \\
\hline Genitivo & Angel eueri & Del Angel \\
\hline Dativo y & Angelni & Al o para el Angel, \\
\hline Accusativo & & Al Angel \\
\hline Vocativo & Angele & Angel vel o Angel \\
\hline Ablativo & Angelni himbo & Del Angel \\
\hline Effectivo $[$ sic $]$ & Angelni himbo & En, por o con el Angel \\
\hline
\end{tabular}

26. El análisis más acertado de caso y declinación en las gramáticas misioneras se lo debemos al erudito estudio de Suárez (1992:110-120, y más en particular págs. 111-112 y 120). Por sus conocimientos no sólo filológicos sino también filosóficos y su intuición investigadora, Suárez enmarca el caso y la declinación dentro de la separación doctrinal que reconocen los misioneros entre los planos formal y semántico, que, en su opinión, «fueron claramente distinguidos en las gramáticas renacentistas espańolas». También menciona en la nota 109 la división universal de casos que efectúa el Brocense en la Minerva, según la cual es necesario que se hallen el mismo número de casos en todas las lenguas.

27. Al dividir el número de casos en siete, Lagunas sigue la tradición de algunos gramáticos latinos y del propio Nebrija (quien, en sus Introducciones latinas, desdobla los valores del ablativo en un caso ablativo propiamente dicho y en un caso efectivo, el cual recoge sobre todo el instrumento con que se hace algo y el acompańamiento). 
En realidad, lo que hay que buscar aquí es una explicación a la contradicción que observa Monzón desde el propio contexto teórico-práctico en el que se encuentra el misionero.

Cuando Gilberti (1558, Segunda Parte, 57r-60r; véase 1987) escribe que en esa lengua sólo hay tres casos (nominativo, acusativo y vocativo), está utilizando la palabra caso no en el sentido conceptual, sino en el de terminación casual o declinación. Es decir que teóricamente (si entendemos declinación en el sentido estricto de la tradición) en esta lengua sólo hay tres terminaciones casuales que son ausencia de marca para el nominativo, $-n i$ para el acusativo (el dativo y el ablativo se derivarían del acusativo) y $-e$ para el vocativo. Por otro lado, al parecer siguiendo el análisis que efectúa Nebrija de caso, declinación y preposición en sus Gramáticas latina y castellana, Lagunas (véase 2002, Primera Parte, Cap. 3:57 y 58) admite un cuarto caso, el genitivo, ya que la significación de caso puede también expresarse formalmente por medio de partículas independientes como eueri para el genitivo, pues, según afirma en este capítulo sobre el nombre y su declinación, para el genitivo añaden la partícula o posposición eueri al nominativo como Angel eueri. En fin, otras partículas independientes (como himbo) no expresarían valores de caso sino que ayudarían a dar variedad de significado a dichos valores (cf. en este mismo sentido el análisis que realiza Nebrija de las preposiciones latinas $a b$, ex, pro o de las castellanas contra, entre, cerca). En resumen, para Lagunas, el nominativo, el dativo, el acusativo y el vocativo llevan terminación de caso, el genitivo se indica mediante una partícula, y el ablativo y el efectivo llevan tanto terminación de caso como partícula, esta última añadiendo variedad al significado casual ${ }^{28}$.

En el paradigma anterior, Lagunas presenta la declinación o expresión formal del concepto caso de forma muy general y práctica para que a través de él, por lo menos, los misioneros se instruyan lo suficiente para entenderse y comunicarse con los indígenas de manera efectiva aunque algo inexacta. Ahora bien, en su Arte, encontramos apreciaciones y precisiones dentro del modelo doctrinal de su tiempo, que tenidas en cuenta, permitirían a los evangelizadores expresarse con «reglas de la elegancia para hablar congruamente» (Primera Parte, Cap. XVII:125; en Lagunas 2002). Así, en la Primera Parte, Caps. 3:58-59 y 6:61 y Tercera Parte, Cap. 1:221, el fraile

28. Lagunas también sigue la tradición de Nebrija al entender declinación no sólo en el sentido de terminación de caso sino también de terminación que marca la pluralidad, pues en la Segunda Parte, Cap. 6:159 de su Arte (véase 2002) expone que el michoacano «tiene variación de casos en la declinación", pero que la pluralidad en esa lengua no se manifiesta por medio de la declinación o terminaciones sino a través de adverbios con el significado de «mucho, muchas, abundancia». 
franciscano trata del oficio de los casos donde ofrece sus valores nocionales y su verbalización en dicha lengua, manifestando que en michoacano no hay ablativo, ya que por ejemplo la oración de pasiva nunca lleva agente, pues quien hace algo se expresa normalmente por el nominativo; se dice, continúa éste, yo soy amado, no señalando de quien, dado que para señalarlo hay que decir Dios me ama. También indica que los nombres racionales carecen de caso efectivo que tiene el valor 'con que' (y no con quien), 'a donde' o 'en que hacemos algo'. Y termina afirmando que lo que algunos llaman ablativo, no tiene en realidad el valor de ablativo, ya que "Hymbo ańadido sobre el dativo o el acusativo, sirve como en el latín propter, vel pro», como en Pedron hymbo 'por Pedro', es decir que posee el valor 'por causa de Pedro' o 'en lugar de Pedro' ${ }^{29}$.

Desde su propia perspectiva doctrinal, queda patente que la palabra «caso» se emplea en un doble sentido por los misioneros: 1) caso en el sentido formal de marca particular de cada lengua; aquí es más frecuente el uso del término declinación o partícula, siguiendo la tradición latina y al propio Nebrija, y 2) caso con la acepción de valor nocional de carácter universal. Así pues, cuando tanto Gilberti como Lagunas sostienen que en michoacano no hay más de tres o cuatro casos respectivamente, hablan en el sentido 1). Por otro lado, cuando tanto Gilberti como Lagunas ofrecen el paradigma de la declinación, éstos ejemplifican cómo los oficios o valores nocionales de los casos (sentido 2) se verbalizan o tienen expresión particular en dicho idioma por medio de declinaciones o posposiciones, o cómo a dichos valores universales se le puede añadir, a la vez, variedad de significación mediante otras posposiciones ${ }^{30}$.

29. El mismo diseño había utilizado anteriormente Gilberti, quien, siguiendo la tradición renacentista, presenta los rudimenta o lo básico de la declinación nominal en la Parte Primera, 12, y el análisis más detallado con los usos en la Parte Segunda, 57r-60r. En su Arte, Lagunas no sólo usa el término «elegancia» con el valor que le otorga el humanista Lorenzo Valla (1407-1457) de hablar una lengua con congruencia y propiedad, sino que también emplea la expresión latina Copia verborum o abundancia de palabras en el sentido de recurso para añadir variedad estilística. En el renacimiento, Desiderio Erasmo (1466-1536) puso de moda la expresión Copia verborum para referirse a listas de palabras sinónimas y frases que, por extensión, llegaría a significar igualmente glosarios y diccionarios.

30. Suponemos que al haber elegido ángel como modelo paradigmático, Lagunas ofrece la posibilidad de presentar el caso efectivo que no hubiera podido ejemplificar con una palabra como cuiripu 'persona', dado que el efectivo, según él, sólo se aplica, como dijimos, a entes no racionales como ángel o caballo, o a inanimados como piedra (2002, Primera Parte, Cap. IV:61). Así, traslada la idea de que cualquier tipo de espíritu o ser de naturaleza no material, algo importante al hablar del cristianismo y de las religiones indígenas, se declinan en el caso efectivo. En fin, Lagunas señala que el efectivo se forma del nominativo «con esta partícula Himbo; ut cavallo hymbo, i.[e.] en el caballo, con el caballo...Porque este modo en 


\section{COMENTARIOS FINALES}

Los misioneros eran hijos de su propio entorno epistemológico en el que lo nocional, lo inteligible, tenía preponderancia sobre la forma observable o el conocimiento sensible, y de sus propias necesidades prácticas de docencia, que convertían al latín y a las lenguas europeas en el medio contrastivo más eficaz para el rápido aprendizaje por los frailes de las lengua indígenas. Hubiera sido utópico que trabajaran con otros modelos teóricos surgidos de los nuevos cambios que se fraguaron en los campos de la filosofía y de las ciencias en los siglos XVI, XVII y XVIII; cambios que trajeron como consecuencia un mayor acento en el conocimiento y origen de las ideas a través de la observación y de lo sensorial más que en las operaciones mentales, cuyas consecuencias lingüísticas son un notable énfasis en la forma y en el verbo exterior en detrimento del verbo interior o lo nocional universal. En Essay Concerning Human Understanding (1690), el filósofo inglés John Locke (1632-1704) actuó como transmisor y divulgador de las ideas que ya se respiraban en el ambiente de la época, contribuyendo a que se produjera dicho cambio epistemológico. Con su doctrina empirista y sensualista, Locke intentaba basar el conocimiento u origen de las ideas en la observación del mundo sensible a partir de los sentidos y reducir las operaciones mentales del mundo inteligible, en dicho conocimiento, a su menor expresión posible. Esta práctica de la observación y de la experimentación ya había proporcionado magníficos resultados en el campo de las ciencias naturales como en la botánica, la zoología, la física y la geología así como en la astronomía por citar varios ejemplos.

Es probable que a la pérdida de adeptos al innatismo lingüístico (véase Formigari 1970) y al historicismo sacro (que sacralizaba la historia al intentar reconciliarla con el Génesis) no sólo contribuyera el nuevo ambiente intelectual de los siglos XVII y XVIII sino también la labor de los misioneros de los siglos XVI y XVII, quienes con su gramáticas y diccionarios empezaban a mostrar, gradualmente, a los lectores europeos, dinámicas formales de idiomas de distintos lugares y regiones geográficas con sus correspondientes estructuras semánticas paralelas al nivel de lo particular que eran susceptibles de sistematización y generalización, aspectos que supieron extraer de sus gramáticas algunos de los seguidores de la nueva corriente empirista y sensualista como el mismo Guillermo Humboldt (cf. Breva 1999 y

los racionales por el Effectivo, se usa con Adverbios congregandi [de juntar]. Ut Mario vel Hyngun, i.[e.] juntamente» (2002, Primera Parte, Cap. III:58). Es decir que en michoacano para hablar elegantemente se dice Pedro y Juan conjuntamente, no empleándose con quien (el caso efectivo) sino el adverbio conjuntamente para indicar acompańamiento. 
2004:61-62). El propio análisis de los misioneros, un mejor conocimiento paulatino de los sonidos, de las estructuras morfológicas, de la sintaxis, de la semántica, de los rasgos sociolingüísticos hizo ver a los investigadores que las lenguas poseían dinámicas independientes con sus propios sistemas y subsistemas que, a veces, eran compartidos por otras lenguas. Es decir, que los misioneros fueron uno de los eslabones necesarios de una cadena que favoreció el desarrollo de la lingüística posterior.

Pierde fuerza la creencia de que desde el marco nocional se explican mejor los rasgos particulares de las lenguas que desde el formal. Surge otro tipo de lingüística que valora la observación empírica en detrimento del innatismo. En lugar de gramática universal a la manera medieval y renacentista, justificable cuando se conocían menos lenguas, se empezará a promover la búsqueda de los rasgos generales de las lenguas sobre la base de sus aspectos formales. La tipología lingüística moderna y la lingüística general fundamentadas en la observación empírica de las lenguas como intentaron practicar cierto número de lingüistas en los siglos XVIII y XIX, incluido el propio Humboldt, todos ellos muy interesados en la labor lingüística y etnológica de los misioneros, hubiera sido impensable o hubiera sufrido retrasos sin el trabajo previo de estos primeros misioneros (cf. Breva 2002).

En resumen, corrientes lingüísticas y tradiciones gramaticales tienen que ser evaluadas por lo que son sus propios méritos y logros, y dentro de su propio contexto epistemológico. De otro modo, nos arriesgamos a malinterpretarlas o a descubrir determinados errores e inexactitudes en ellas que impiden contemplar el lugar que les corresponde en la historia de una disciplina. 
BULLETIN HISPANIQUE

\section{BIBLIOGRAFÍA}

Acosta, José de, 1954. Obras del Padre José de Acosta. Estudio preliminar y edición del Padre Francisco Mateos. (Biblioteca de Autores Españoles, Tomo 73). Madrid: Ediciones Atlas.

Aguirre Beltrán, Gonzalo, 1983. Lenguas vernáculas. Su uso y desuso en la enseñanza: la experiencia de México. México D.F.: Centro de Investigaciones y Estudios Superiores en Antropología Social.

Alvar, Manuel, 1992. «Nebrija y tres gramáticas de lenguas americanas «náhuatl, quechua y chibcha)». En Alvar, Manuel (coord.), Estudios Nebrissensis. Madrid: Ediciones de Cultura Hispánica, págs. 313-339.

Anónimo (¿Alonso Barzana?). 1586. Arte, y vocabulario en la lengua general del Perú llamada Quichua, y en la lengua Española. En los Reyes (= Lima): Antonio Ricardo.

Arens, Hans, 1980. "Verbum cordis': Zur Sprachphilosophie des Mittelalters». Historiographia Linguistica 7:1/2.13-27.

Breva-Claramonte, Manuel, 1994. La didáctica de las lenguas en el Renacimiento: Juan-Luis Vives y Pedro Simón Abril. Con selección de textos. Bilbao: Universidad de Deusto.

- 1999. «El análisis de lenguas indígenas en Lorenzo Hervás (1735-1809) y sus repercusiones en Europa». En Fernández, M. y otros (eds.), Actas del I Congreso Internacional de la Sociedad Española de Historiografía Lingüistica (A Coruña, 18-21 de febrero de 1997). Madrid: Arco/Libros, págs. 161-171.

- 2001. «El signo en el nacimiento de la gramática 'general': De Platón al Brocense». En Marina Maquieira Rodríguez y otros (eds.), Actas del II Congreso Internacional de la Sociedad Española de Historiografía Lingüistica, León, 2-5 de marzo de 1999. Madrid: Arco/Libros, págs. 17-33.

- 2002. «Lorenzo Hervás (1735-1809) y la tipología lingüística moderna». En Bernabé, Alberto y otros (eds.), Presente y futuro de la lingüistica en España. La sociedad de Lingüistica, 30 años después. Actas del II Congreso de la Sociedad Española de Lingüistica (Madrid, 11-15 de diciembre de 2000), vol. 2. Madrid: Sociedad Española de Lingüística, págs. 671-679.

- 2004. "Contexto epistemológico y modelo doctrinal de las ideas lingüísticas de Lorenzo Hervás (1735-1809)». Revista Española de Lingüística 34.39-68.

Calvo Pérez, Julio, 1997. «La gramática aimara de Bertonio (1603) y la escuela de Juli». En Zimmermann (1997b), págs. 321-338.

Carochi, Horacio, 1983. Arte de la lengua mexicana con la declaración de los adverbios della. Edición facsimilar de la publicada por Juan Ruyz en la ciudad de México, 1645. Con un estudio introductorio de Miguel León-Portilla. México D.F.: Universidad Autónoma de México.

Dedenbach-Salazar Sáenz, Sabina, 1997. "La descripción gramatical como reflejo e influencia de la realidad lingüística: la presentación de las relaciones 
hablante-enunciado e intra-textuales en tres gramáticas quechuas coloniales y ejemplos de su uso en el discurso quechua de la época». En Zimmermann (1997b), págs. 291-319.

Escalígero, Julio-César, 1584 [1540]. De causis linguae Latinae, libri tredecim. [Heidelberg:] Apud Petrum Santandreanum.

Esparza Torres, Miguel Ángel, 2003. «Lingüística en la frontera: sobre las motivaciones, argumentos e ideario de los misioneros lingüistas». Romanistik in Geschichte und Gegenwart 9:1.67-92.

Formigari, Lia, 1970. Linguistica ed impirismo en el seicento inglese (Bibl. di Cultura Moderna, 695). Bari: Laterza.

Galeote, Manuel, 2001. «Proyección lingüística de Nebrija en las Indias: La obra de Alonso de Molina». En Maquieira Rodríguez, M. y otros (eds.), Actas del II Congreso Internacional de la Sociedad Española de Historiografía Lingüistica, León, 2-5 de marzo de 1999. Madrid: Arco/Libros, págs. 423-433.

- 2002-2003. "Alonso de Molina, el Nebrija de las Indias: su labor lexicográfica». Boletín de Filología (Universidad de Chile) 39.399-412.

Gilberti, Maturino, 1987 [1558]. Arte de la lengua de Michuacan. México: Hecha en casa de Ioan Pablos Impresor. Edición facsímil con una introducción histórica por Benedict J. Warren. Morelia, Michoacán, México: Fimax Publicistas Editores.

Griffin, C. 1991, Los Cronemberg. La historia de una imprenta del siglo XVI en Sevilla y Méjico. Madrid: Ediciones de Cultura Hispánica.

González Holguín, Diego 1975 [1607]. Grammatica y arte nueva de la lengua general de todo Peru, llamada lengua quechua, o lengua Inca. [Ciudad de los Reyes (=Lima): Francisco del Canto]. Edición facsimilar, Cabildo Verduz-Georgetown: Franz Wolf, Heppenheim a.d.B.

Hampe Martínez, Teodoro. 1987. «La difusión de libros e ideas en el Perú colonial. Análisis de las bibliotecas particulares (siglo XVI)». Bulletin Hispanique 89/14.55-84.

Hernández de León-Portilla, Ascensión, 2003. «Las primeras gramáticas mesoamericanas: Algunos rasgos lingüísticos». Historiographia Lingüística 30:1/2.1-44.

- y Miguel León-Portilla, 1990. «El Colegio Imperial de Santa Cruz de Tlatelolco». En P. Galeana de Valadés (coord.). Tlatelolco. México: Secretaría de Relaciones Exteriores.

Hernández Sacristán, Carlos, 1997. «Categoría formal, categoría funcional y teoría de la traslación en las primeras gramáticas del náhuatl». En Zimmermann (1997b), págs. 43-58.

Humboldt, Wilhelm von, 1903-1936. Gesammelte Schriften. Leitzmann, Albert y otros (eds.). 17 vols. Berlín: B. Behr.

Lagunas, Iuan Baptista de, 2002 [1574]. Arte en la lengua michuacana. Transcripción: Agustín Jacinto Zavalas. Zamora, Michoacán: El Colegio de Michoacán. (También contiene el Dictionario [sic]). 
Leonard, Irving A., 1942. "Best Sellers of the Lima Book Trade, 1583». Hispanic American Historical Review 22.5-33.

- 1953. "One the Lima Book Trade, 1591». Hispanic American Historical Review 33.511-525.

Mandonnet, R. P. Petrus, 1927. S. Thomae Aquinitatis opuscula omnia. Tomus quintus. Parisiis: Sumptibus P. Lethielleux, Biblipolae Editores.

Mathes, M. 1982, Santa Cruz de Tlatelolco: La primera biblioteca académica de las Américas. México: Secretaría de Relaciones Exteriores.

Mendieta, Fray Gerónimo de, 1870 [hacia 1567]. Historia Eclesiástica Indiana, obra escrita a fines del siglo XVI. La publica por primera vez Joaquín García Icazbalceta. México: Librería Antigua. (Reimpresión facsímil, México, Editorial Porrúa, 1980).

Molina, Alonso de, 1945 [1571]. Arte de la lengua mexicana y castellana. México: En casa de Pedro Ocharte. (Reproducción facsímil, Madrid, Ediciones de Cultura Hispánica).

- 2001 [1555]. Aqui comienza un vocabulario en lengua castellana y mexicana. México: Por Juan Pablos. Edición facsímil con estudio preliminar de Manuel Galeote (Analecta Malacitana, Anejo 37). Málaga: Universidad de Málaga.

Monzón, Cristina. 1997. «Terminología y análisis de la estructura morfológica en el “Arte en Lengua Michoacana» de fray Juan Baptista Lagunas (siglo XVI)». En Zimmermann 1997b, págs, 133-145.

Nágel Bielicka, Federico Beals. 1994. «Aprendizaje del náhuatl entre franciscanos y jesuitas en la Nueva España». Estudios de Cultura Nábuatl 24.419-441.

Nebrija, Antonio de. 1980 [1492]. Gramática de la lengua castellana. Estudio y edición de Antonio Quilis. Madrid: Editorial Nacional.

- 1981 [1481]. Introductiones Latinae. Salmanticae. Edición facsimilar. Salamanca: Universidad de Salamanca.

- 1996 [1488]. Introducciones latinas contrapuesto el romance al latín. Esparza, Miguel Ángel \& Vicente Calvo (eds.). (Materialen zur Geschichte der Sprachwissenschaft und der Semiotik, Band 7): Münster: Nodus Publikationen.

Olmos, Fray Andrés de. 1993 [1547]. Arte de la lengua mexicana. Edición y estudio introductorio, transliteración y notas de Ascensión y Miguel León Portilla. Madrid: Ediciones de Cultura Hispánica, Instituto de Cooperación Iberoamericana.

Padley, G. Arthur. 1976. Grammatical Theory in Western Europe 1500-1700: The Latin Tradition. Cambridge: Cambridge University Press.

Prisciano (siglo VI). 1855-1859. Institutiones grammaticae. En Heinrich Keil (ed.), Grammatici Latini, 7 vols. Lipsiae: In aedibus Teubneri, Vols. 2-3.

Rodrigues, Aryon D. 1997. «Descripción del tupinambá en el periodo colonial: el Arte de José de Anchieta». En Zimmermann (1997b), págs. 371-400.

Ruiz de Montoya, Antonio, 1993 [1640]. Arte de la lengua guarani. Edición facsimilar. Asunción: Centro de Estudios Paraguayos «Antonio Guasch».

Samaranch, Francisco de P. (trad.). 1964. Aristóteles: Obras. Traducción del griego, 
estudio preliminar, preámbulos y notas. Madrid: Aguilar.

San Agustín de Hipona, 1948. De Trinitate. En Obras de San Agustín en edición bilingüe. Tomo 5. Primera versión española, introducción y notas del padre Fr. Luis Arias. (Biblioteca de Autores Cristianos). Madrid: Editorial Católica.

Sánchez de las Brozas, Francisco, 1986 [1587]. Minerva seu de causis linguae Latinae. Salmanticae: Apud Joannem \& Andraeam Renaut, fratres. Reproducción facsímil, con una introducción de M. Breva-Claramonte. Stuttgart-Bad Cannstatt: Frommann-Holzboog.

- 1995. Mineva o De causis linguae latinae. [Edición bilingüe]. Sánchez Salor, E y C. Chaparro Gómez (eds. y trad.) Cáceres: Institución Cultural «El Brocense», Universidad de Extremadura.

Santo Tomás de Aquino, 1980. S. Thomae Aquinitatis opera omnia, curante Roberto Busa S.I., 7 vols. Stuttgart-Bad Cannstat: Frommann-Holzboog.

Santo Tomás, Domingo de, 1951 [1560]. Grammatica o Arte de la lengua general de los Indios de los Reynos del Peru. Valladolid. Con un prólogo de Raúl Porras Barrenechea. Edición facsimilar. Lima: Universidad Nacional Mayor de San Marcos.

Sarmiento, Ramón, 2000. «Antonio de Nebrija y la lingüística en la época del descubrimiento». En Bagola, Beatrice (ed.), La lingüistica española en la época de los descubrimientos. Actas de Coloquio en honor del profesor Hans-Josef Niederehe, Tréveris, 16 al 17 de junio de 1997. Hamburg: Helmut Buske Verlag, págs. $157-$ 173.

SuÁrez Roca, José Luis, 1992. Lingüistica misionera española. (Colección Basilisco). Oviedo: Pentalfa Ediciones.

Torre Revello, J., 1962. «La enseñanza de lenguas a los naturales de América». Thesaurus (Bogotá) 17/3.501-526.

Urbano, Alonso, 1990 [1605]. Arte breve de la lengua otomi y vocabulario trilingüe español-náhuatl-otomí. Edición de René Acuña. (Instituto de Investigaciones Filológicas, Gramáticas y Diccionarios, 6). México D.F.: Universidad Nacional Autónoma de México.

Villalón, Cristóbal de, 1558. Gramática castellana. Arte breve y compendiosa para saber hablar y escrevir en lengua Castellana congrua y deçentemente. Amberes: En casa de Guillermo Simón.

Zimmermann, Klaus, 1997a. "La descripción del otomí/hñahñu en la época colonial: lucha y éxito». En Zimmermann 1997b, págs. 113-132.

- (ed.). 1997b. La descripción de las lenguas amerindias en la época colonial. (Bibliotheca Ibero-Americana; Vol. 63). Madrid: Iberoamericana; Frankfurt am Main: Vervuert.

Zwartjes, Otto (ed.). 2000. Las gramáticas misioneras de la tradición hispana (siglos XVI y XVII). Ámsterdam: Rodopi.

- 2002. "The Description of Indigenous Languages of Portuguese America by the Jesuits during the Colonial Period: The Impact of the Latin Grammar of Manuel Alvarez». Historiographia Linguistica 29:1/2.19-70. 